\title{
PROPOSTA DE UMA COBERTURA PARAMÉTRICA DE FORMA COMPLEXA DERIVADA DA PROJEÇÃO DE TRIÂNGULOS ISÓSCELES
}

PROPUESTA DE UNA COBERTURA PARAMÉTRICA COMPLEJA DERIVADA DE LA PROYECCIÓN DE TRIÁNGULO ISÓSCELES

PROPOSAL FOR A PARAMETRIC COVERAGE OF COMPLEX SHAPE DERIVATIVE FROM THE PROJECTION OF ISOSCELES TRIANGLES

\section{TRINDADE, SILENO CIRNE}

Arquiteto e Urbanista, Diretor de Projetos da Superintendência de infraestrutura da UFRN; Mestre em Arquitetura e Urbanismo, UFRN. E-mail: silenocirne@gmail.com

\section{BARCA, ANA CLARA DE MELO CALDAS BATISTA}

Engenheira Civil, UFRN. E-mail: anaclaramcb@gmail.com

\section{JONAS JUNIOR, LENILSON MIRANDA}

Arquiteto e Urbanista, Mestrando Programa de Pós-Graduação em Arquitetura e Urbanismo, UFRN; Especialista em MBA em Design Thinking, UnyLeya. E-mail: lenilsonjonas@gmail.com

\section{REIS, MAÍRA NASCIMENTO QUEIROZ}

Arquiteta e Urbanista, Mestranda do Programa de Pós-Graduação em Arquitetura, Projeto e Meio Ambiente, UFRN. E-mail: mairanascimentoarq@gmail.com

\section{RESUMO}

Este artigo tem por objetivo apresentar a proposta de um elemento arquitetônico que conectará os edifícios da graduação e pós-graduação em Arquitetura e Urbanismo da UFRN. Foi parte de uma atividade de extensão vinculada a uma disciplina Oficina de Projeto Computacional. O processo de projeto tem por base o uso da ferramenta de modelagem paramétrica Grasshopper. Com este artigo, poderá se compreender, de modo breve, o processo de projeto do grupo 04, passando pelas diversas etapas: idealização do conceito, estudos de referência, concepção projetual, prototipagem e cálculo estrutural.

PALAVRAS-CHAVE: projeto; parametrização; grasshopper.

RESUMEN

Este documento tiene como objetivo presentar la propuesta de un elemento arquitectónico que conectará los edificios de pregrado y posgrado en Arquitectura y Urbanismo de la UFRN. Fue parte de una actividad de extensión vinculada al curso Taller de Diseño Computacional. El proceso de diseño se basa en el uso de la herramienta de modelado paramétrico Grasshopper. Con este artículo, puede comprender brevemente el proceso de diseño del grupo 04, pasando por las diferentes etapas: idealización de conceptos, estudios de referencia, diseño de proyectos, creación de prototipos y cálculo estructural.

PALABRAS CLAVES: proyecto; parametrización; Grasshopper.

\section{ABSTRACT}

This article aims to present the proposal of an architectural element that will connect the buildings of the undergraduate and graduate Architecture and Urbanism of UFRN. It was part of an extension activity linked to the course Computational Design Workshop. The design process is based on the use of the Grasshopper parametric modeling tool. With this article you can briefly understand the design process of group 04, going through the various stages: concept idealization, reference studies, project design, prototyping and structural calculation.

KEYWORDS: Project; parameterization; grasshopper. 
Este artigo tem por objetivo apresentar uma proposta de um elemento arquitetônico que conectará o edifício dos Laboratórios de Arquitetura e Urbanismo ao novo edifício do programa de Pós-Graduação em Arquitetura e Urbanismo (PPGAU), desenvolvida durante a atividade de extensão: Oficina de Projeto Paramétrico, vinculada à disciplina Oficina de Projeto Computacional, do Programa de Pós-graduação em Arquitetura Projeto e Meio Ambiente (PPAPMA) da Universidade Federal do Rio Grande do Norte (UFRN).

A atividade acadêmica foi organizada pelos Professores Maísa Veloso e Heitor Silva e a ação de extensão coordenada pelo professor Verner Monteiro, todos do Departamento de Arquitetura da UFRN. Tinha por objetivo a elaboração do projeto de uma cobertura de forma complexa, que sirva como passarela de conexão entre os dois prédios, situados no Centro de Tecnologia da UFRN.

Esse texto apresenta brevemente a idealização do projeto proposto pela equipe denominada Grupo 04, de acordo com a distribuição das equipes em sala de aula. O Grupo autor do projeto é formado por Ana Clara, engenheira civil; Lenilson Jonas, arquiteto e urbanista, discente do mestrado acadêmico; Maíra Nascimento, arquiteta e urbanista, discente do mestrado profissional; e Sileno Cirne; coordenador de projetos da Superintendência de Infraestrutura da UFRN.

O exercício de concepção estabelecia algumas restrições a serem levadas em consideração, quanto à préexistência dos edifícios a conectar: características dos edifícios existentes, previsão de expansão do novo edifício, topografia existente, sistema de drenagem, agenciamento do piso; árvore existente e paisagismo proposto para o terreno. Quanto ao elemento arquitetônico a ser projetado deveriam ser levadas em conta, a localização e solução das fundações, as características dos materiais - madeira como material base, o cobrimento em telha e a vegetação do tipo trepadeira, os tipos de nós utilizados nas conexões estruturais, a montagem e o tempo de execução, mão de obra da UFRN sem possibilidade de fabricação digital.

Outra restrição importante era a obrigatoriedade de utilizar como meio de representação da concepção a modelagem paramétrica (Software Rhinoceros 6, Grasshopper e Karamba 3D) e que a forma do objeto arquitetônico tenha possibilidades de variação geométrica definida por parâmetros.

Desde modo, foi adotada pela equipe uma metodologia de projeto em concepção colaborativa, utilizando os conhecimentos precedentes dos projetistas e propondo ideias acessíveis à realidade local e refletindo os potenciais de uso da área. As atividades foram organizadas dentro do processo de projeto na ordem de definição do conceito, modelagem da estrutura e definição do produto. A estrutura do texto está organizada na apresentação da área; idealização do conceito; explicação do processo, apresentação dos setores de projeto; e, ao fim, as considerações finais.

\section{DESENVOLVIMENTO}

\section{Área de projeto}

Para o grupo, Integração é a palavra que mais sintetizava a ideia do projeto. Procurou-se idealizar um projeto que não apenas ligasse as duas edificações, mas que funcionasse também como espaço de convívio. Além disso, buscou-se uma proposta passível de ser expandida e que seus módulos pudessem ser replicados em outras áreas. Como exercício foi proposto elaborar o projeto de uma cobertura que servisse como passarela, integrando o prédio do Laboratório de Arquitetura (vulgo "Galinheiro") e da pós-graduação (PPGAU), tendo como base uma maquete eletrônica da área e as planta-baixas com os diferentes níveis.

Dispondo desse material em mãos, priorizou-se conhecer primeiro o local onde o projeto seria inserido, a fim de auferir impressões próprias sobre a área. Durante a visita, constatou-se que essa passarela não apenas conectaria duas edificações, mas estaria inserida em uma estrutura mais complexa que se liga a outras áreas adjacentes. Dessa forma, a cobertura poderia ser vista de pelo menos seis ângulos diferentes (Figura 1):

- $\quad 1^{\circ}$ - Vista de quem passa por fora do Laboratório de Arquitetura;

- $\quad 2^{\circ}$ - Vista da praça ao lado do PPGAU;

- $\quad 3^{\circ}$ - Vista de quem está saindo da porta do Laboratório de Arquitetura;

- $\quad 4^{\circ}$ - Vista de quem está saindo da porta do prédio do PPGAU;

- $\quad 5^{\circ}$ - Vista da praça entre o Bloco $\mathrm{H}$ e o Laboratório de Arquitetura;

- $6^{\circ}$ - Vista de quem está saindo do Bloco de aulas H no sentido do PPGAU. 
Figura 1: Primeiro croqui traçando os visuais da área.

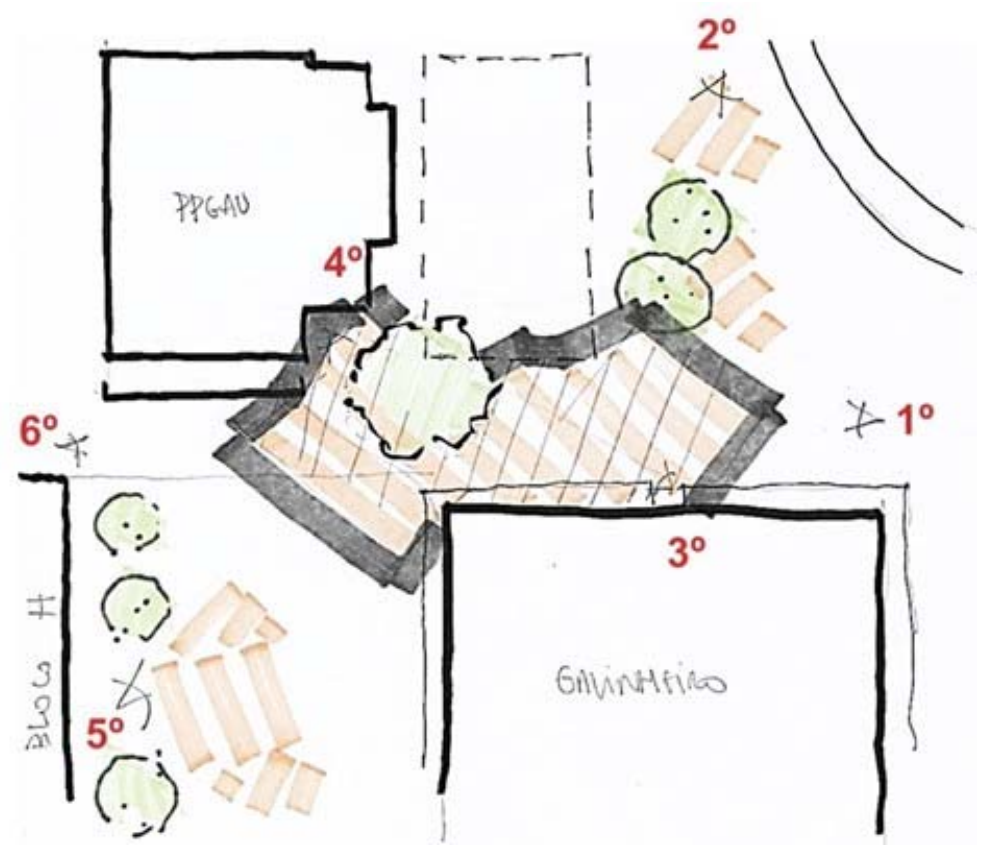

Fonte: Elaborado pelo grupo, 2019.

\section{Conceito e Partido}

Após a visita ao local, procurou-se definir o conceito do projeto "Integração, que já foi citado no tópico anterior. Segundo Mcginty (1984) o conceito é uma parte importante do projeto arquitetônico. "Conceito sugere um modo específico de conjugar exigências programáticas, contextos e crenças". Assim como Brandão (2000) afirma que os conceitos "não surgem do nada, mas da reflexão sobre a nossa própria experiência dos espaços e daquilo que nos fornece a tradição que Ihes concerne". O conceito é um recurso abstrato que funciona como um eixo no qual o processo de elaboração projetual se estrutura. A sua aplicação tem como resultado uma proposta que cumprem a necessidade imposta, e que consegue refletir a sua sensibilidade conceitual.

Para a definição do conceito, buscou-se um tipo de expressão capaz de sugerir a intenção do projeto e impulsionar as ideias na direção das soluções projetuais. Nesse sentido Favero e Passaro (2005) defendem que: um argumento, seja perceptivo ou conceitual deve em princípio "sustentar" uma obra arquitetônica, através da definição semanticamente, por meio da linguagem escrita e das palavras-chave relacionadas ao projeto.

Enquanto o conceito serve como estímulo na geração de ideias, o partido é a manifestação dessa ideia. "Partido seria uma consequência formal derivada de uma série de condicionantes ou de determinantes; seria o resultado físico da intervenção sugerida" (LEMOS, 2003, p. 40).

Segundo SILVA (1998), o partido sintetiza as características principais do projeto, o próprio conceito representado, que "deriva do processo de elaboração mental que procura sintetizar o resultado das principais decisões tomadas pelo projetista enquanto procura definir os traços essenciais do objeto em concepção". "Um desenho que, embora seja apenas um rabisco, contém o caráter do projeto como, por exemplo, a sua definição estrutural. É o principal desenho do arquiteto, os demais virão em decorrência deste" (AMARAL, 2007, on-line).

Desde o início da concepção, procurou-se estabelecer como partido algum componente que dialogasse com os aspectos visuais dos prédios pré-existentes. Para isso, buscou-se o elemento de maior destaque no prédio do Laboratório de Arquitetura, a sua cobertura marcada pelo uso de tesouras metálicas, cujo desenho é uma composição de diversos triângulos (Figura 2). Assim, o triângulo foi adotado como a forma geométrica que definiria todo o desenho da passarela. 
Figura 2: Imagens do Bloco dos Laboratórios da Arquitetura (Galinheiro) com destaque para tesoura metálica.

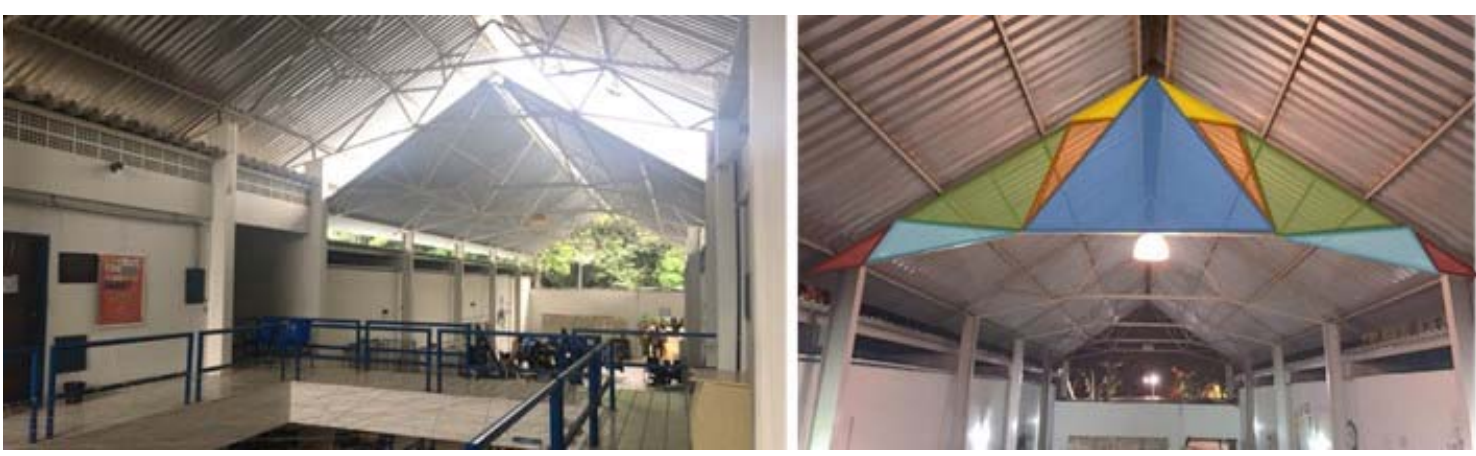

Fonte: Elaborado pelo grupo, 2019.

A partir dessas informações foram geradas algumas diretrizes projetuais:

- Integrar a cobertura às edificações existentes;

- Possibilitar a expansão da coberta, caso fosse necessário;

- Valorizar as visuais da estrutura em diversos ângulos diferentes;

- Conectar a passarela com os demais acessos existentes;

- Criar um espaço de convivência sobre a cobertura.

\section{Precedentes projetuais}

Após definição do conceito, a equipe buscou alguns precedentes que pudessem ajudar a desenvolver a proposta. Segundo Andrade et al (2011), projetar baseado em precedentes apoia-se na ideia de que a maioria dos problemas de projeto apresenta similaridades com outros precedentes. Novas soluções podem ser baseadas em experiências anteriores que servem para resolver novos problemas de projeto.

O primeiro passo foi buscar referências formais, de modo que fosse possível identificar formas que permitissem a aplicação do conceito do grupo em uma estrutura espacial de forma complexa. Para essa busca foi utilizada a rede social Pinterest, já que esta é um banco de dados de imagens, que fornece desde imagens de construções, desenhos de projeto, a protótipos e outros.

Naturalmente as imagens de protótipos foram as que mais atraíram a atenção da equipe, melhor relacionando a ideia conceito, ao processo de projeto com parametrização e função básica de passarela solicitada na restrição inicial de projeto. Andrade et al (2011) afirmam que os protótipos são as formas mais comuns de emprego de casos precedentes em arquitetura. Seu uso é bastante recorrente quando existe similaridade de características entre um problema de projeto novo e um antigo.

Na pesquisa, buscaram-se estruturas de passarelas formadas a partir da união de triângulos, já que era figura geométrica extraída da tesoura metálica do prédio existente. Com isso, foram encontrados alguns modelos de protótipos de diversos materiais que serviram inicialmente de referências formais. Através destas imagens de modelos surgiu a reflexão da necessidade estrutural dos nós de encontro dos triângulos, do travamento através de barras horizontais e a necessidade de pilares que sustentem a passarela.

Após a compreensão das referências formais, procuraram-se precedentes de projetos que pudessem auxiliar na reflexão estrutural e funcional. Um dos projetos utilizados como precedentes foi o Pormetxeta Square, de autoria do MTM Architects + XPIRAL. É uma praça com aproximadamente $25.000 \mathrm{~m}^{2}$, localizada em Biscaia, Espanha. Neste projeto, foi instalada uma estrutura de passeio coberto no espaço da praça criado para permitir fluidez e mobilidade da cidade para o rio.

A estrutura tem função de ligar os acessos e aproximar as edificações do entorno e ruas. E diminuiu a relação de desnível que possuía no espaço antes vago. Com essas relações, foram criados pequenos espaços públicos que servem de pontos de encontro, suportes de descanso, estadias ao ar livre, além de constituírem um elemento que tem função de equipamento urbano.

Outro ponto importante que a estrutura na praça trouxe à tona foi a preocupação do pilar receber carga em mais de um ponto, já que este possui uma forma semelhante a uma árvore, com sua fundação originando de uma base única, onde o pilar se ramifica em quatro pontos de apoio.

Outro projeto que serviu de precedente foi o Living Garden, de autoria do MAD Architects, que trouxe como contribuição a compreensão dos encontros e conexões entre as peças de madeira e a potencialidade de permanência sob a estrutura. É uma proposta de residência para Pequim, China, que quebra a noção da casa 
tradicional, desconsiderando as paredes e prevendo uma atmosfera em pleno ar. Possui uma coberta curvada em grade de madeira revestida em vidro translúcido que protege o interior da chuva, mantendo abertura para o céu e os seus arredores, integrando-se com a paisagem do entorno.

A estrutura da coberta trouxe compreensão quanto às conexões das peças de madeiras maiores e com maior função de sustentação e de borda às peças de madeira de menor porte, as grades, com função de sombreamento e sustentação do telhado.

Nestes casos, os antecedentes foram de grande importância, pois apresentam, assim como destacam Andrade et al (2011), algumas similaridades com a proposta, com diferentes formas e contexto, o que ocorre de forma indireta, servindo como substrato para novas ideias.

\section{Processo de projeto}

Com isso, iniciou-se o processo de projetação. Foi realizada uma visita no local com a intenção de identificar as áreas onde poderia ser locada a estrutura, através dos pilares em terra ou viga fixadas nas paredes existentes. A Figura 3 mostra a marcação das áreas com potencial para receber os apoios marcada em tom marrom sobre a planta de levantamento planialtimétrico cedida pela organização.

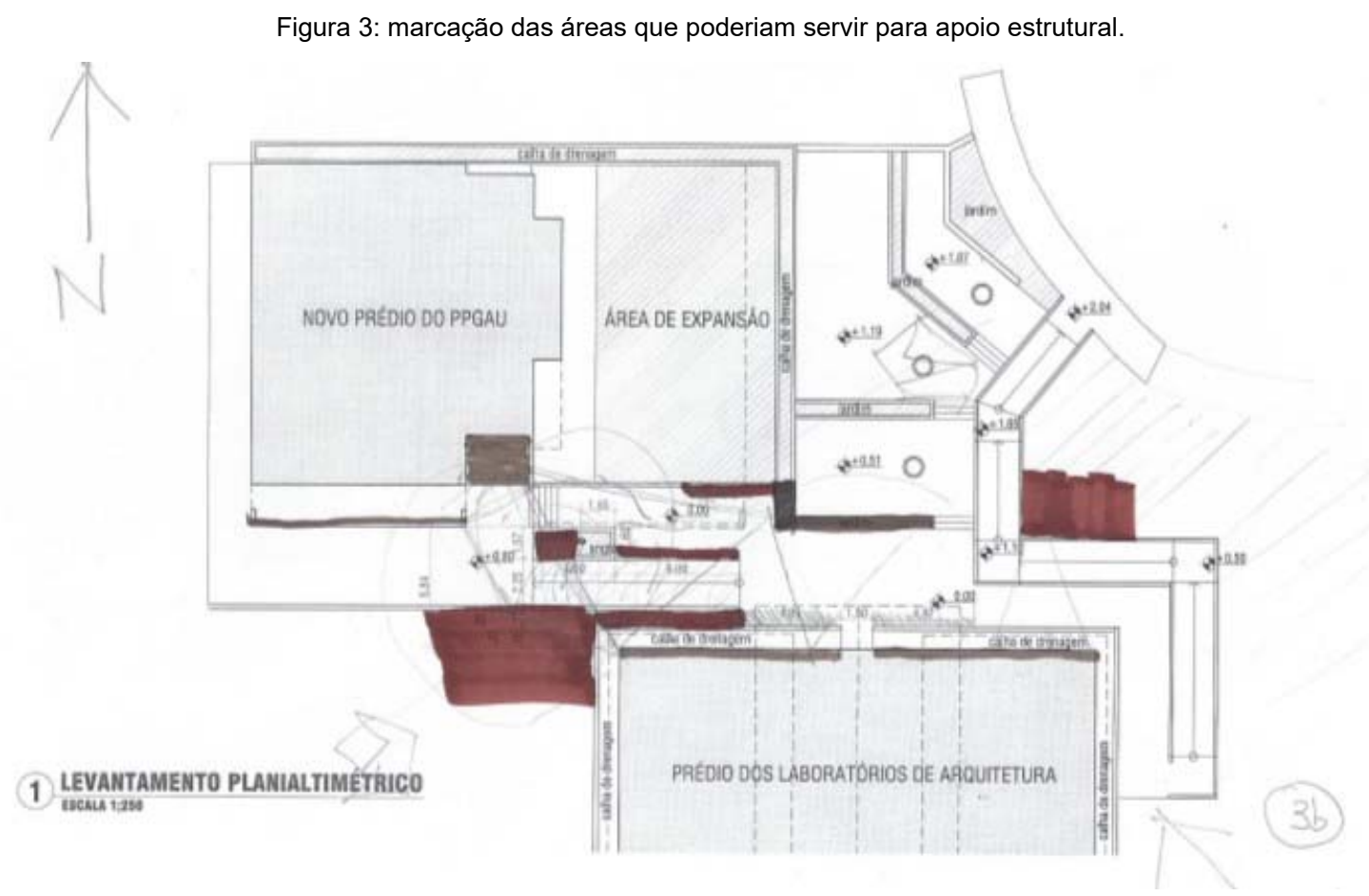

Fonte: Elaborado pelo grupo, 2019.

Uma restrição de projeto era o desenvolvimento com auxílio de computador através de algoritmos e softwares paramétricos. Neste caso, considera-se como uma restrição radical (LAWSON, 2011) gerada pelo legislador, função assumida pela organização da atividade de extensão. Porém no processo de projeto também se utilizou de outras ferramentas complementares para auxiliar a total compreensão e dialogo entre integrantes do grupo.

Durante todo o processo, foram utilizados desenhos à mão livre. Já que este é um ótimo meio para organizar e expressar pensamentos e percepções visuais de maneira rápida e sucinta (CHING, 2012). Os primeiros esboços da planta de cobertura propunham distribuir os nós (pontos na Figura 4) nas áreas antes selecionadas para locação das fundações. Pensando na construtibilidade do projeto essa ideia apresentou um problema no qual todas as peças teriam diferentes dimensões e encaixes das suas conexões. 


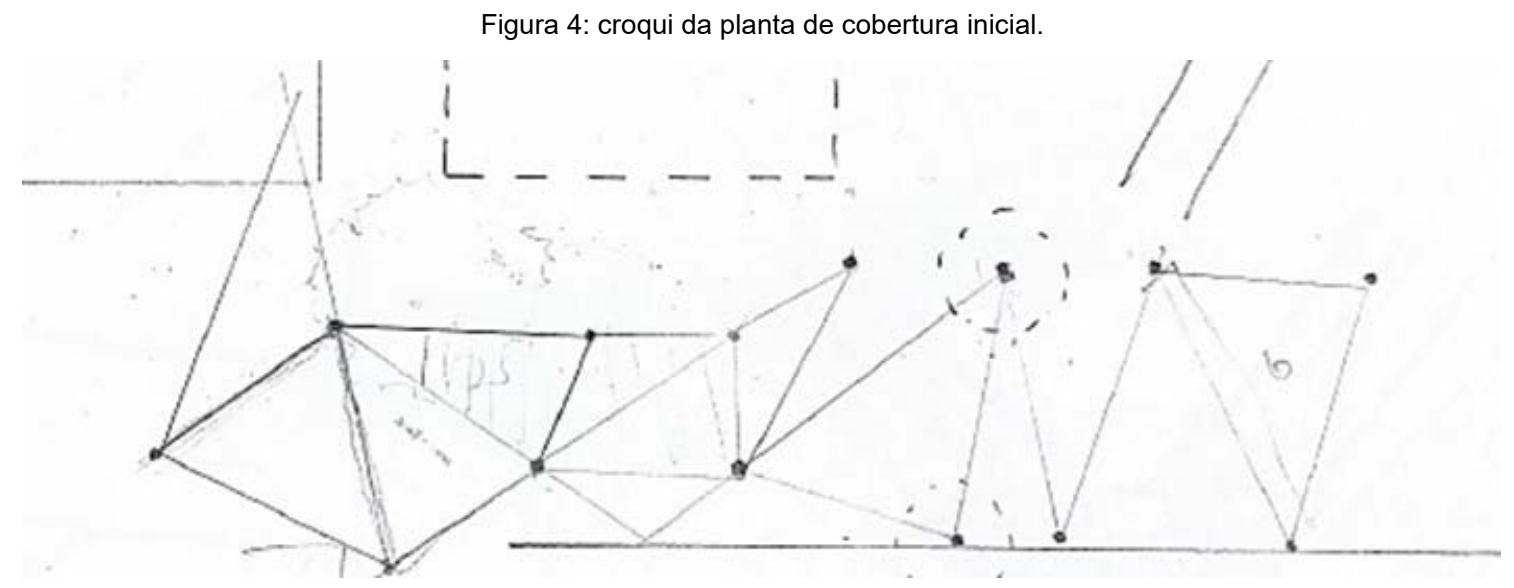

Fonte: Elaborado pelo grupo, 2019.

Quando foi necessário compreender a escala do projeto e medidas mais precisas, usou-se o software AutoCAD (Figura 5 e Figura 6). A partir desta etapa pode-se a ter maior precisão na medição das peças de madeiras que seriam utilizadas, e com isso a equipe percebeu que para uma melhor conformação do projeto a estrutura total do projeto seria formado por um módulo de triangulo isósceles com seus lados iguais sendo formados pela medida máxima estipulada na lista de materiais disponibilizada e o menor lado do triângulo é formado pelo alinhamento, observado em vista de topo, dos pilares ou do engaste das terças nas faces das edificações existentes (Figura 6). A todo momento, as discussões de projeto foram considerando as disposições em planta, a exequibilidade e a busca de uma volumetria complexa.

Figura 5: Estudo inicial da cobertura no AutoCAD.

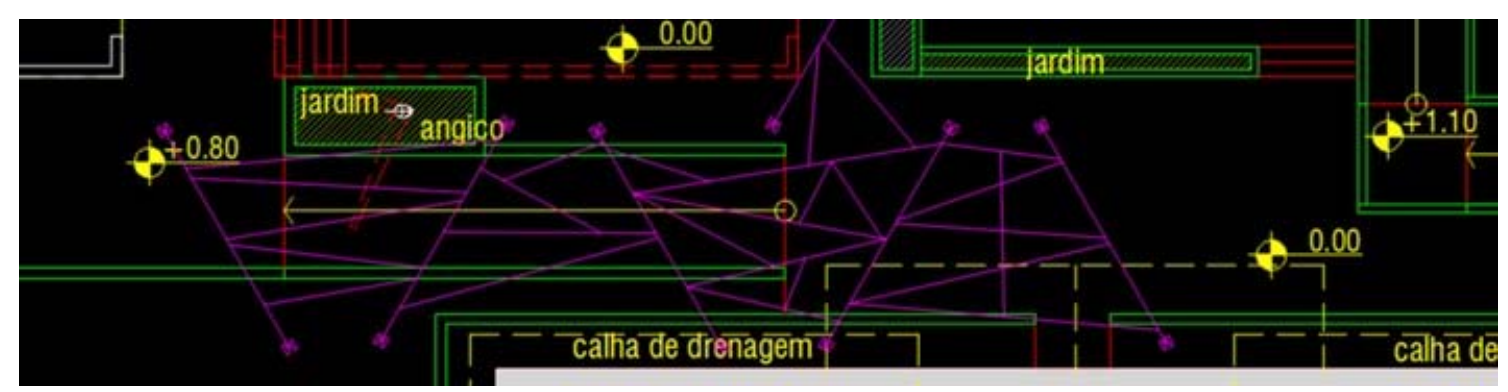

Fonte: Elaborado pelo grupo, 2019.

Figura 6: Estudo preliminar de planta de cobertura no AutoCAD.

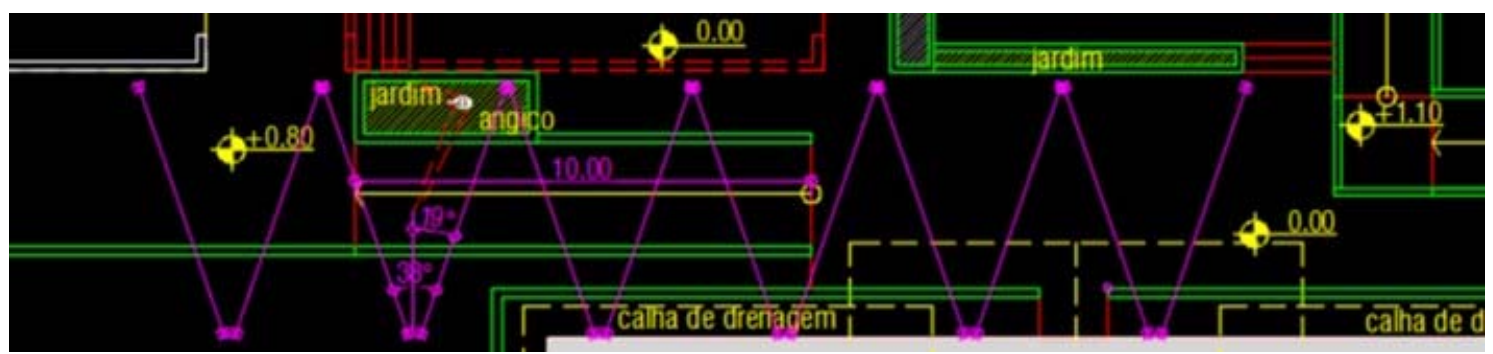

Fonte: Elaborado pelo grupo, 2019.

Quando não foi mais possível o entendimento da volumetria através dos croquis, foi utilizado o Software SketchUp modelando uma volumetria esquemática (Figura 7) que ajudasse a todos entenderem a volumetria básica a ser trabalhada. 
Figura 7: Estudo de volumetria modelada através do software SketchUp.

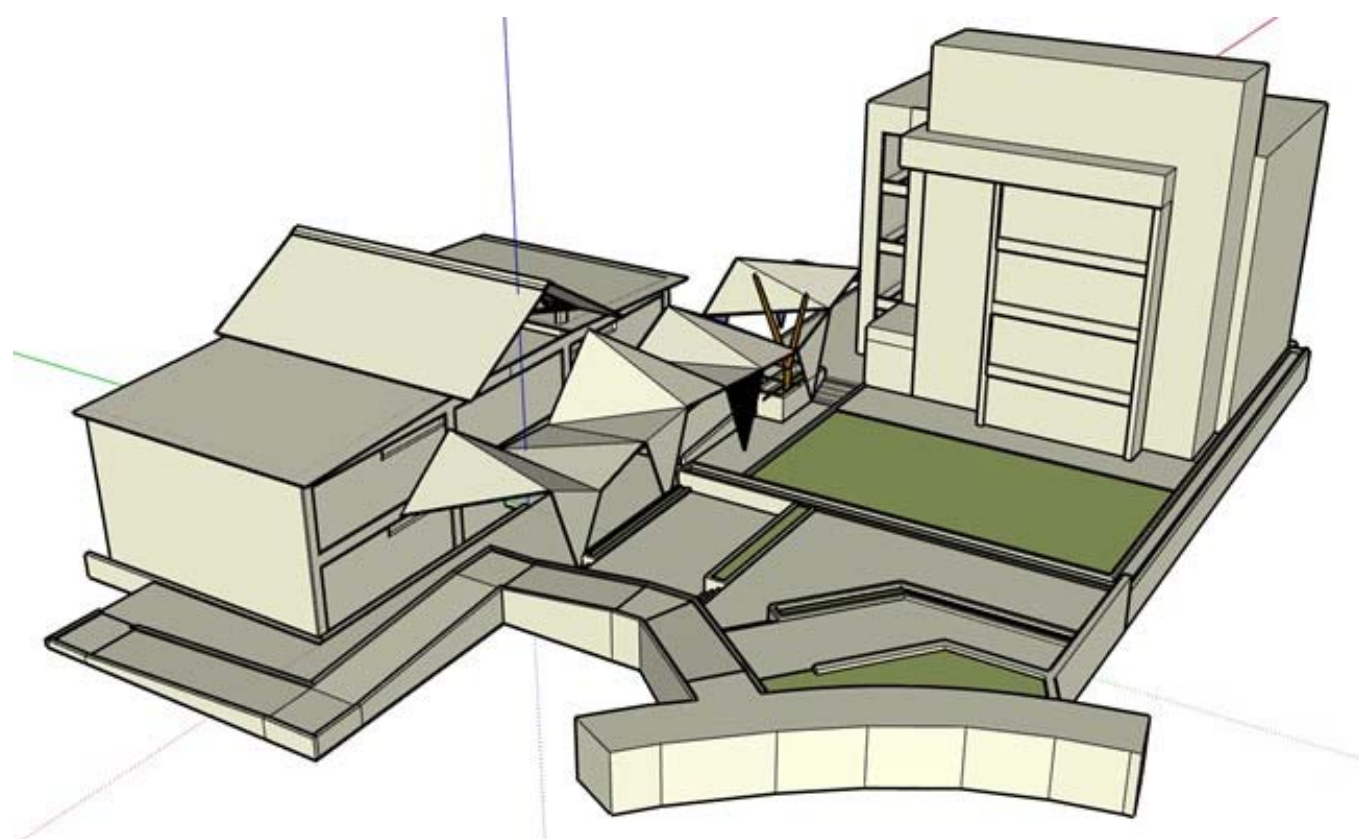

Fonte: Elaborado pelo grupo, 2019.

A partir desses estudos iniciais, os projetistas puderam iniciar a elaboração da rotina de algoritmo do modelo de projeto. Segundo Lee e Beaurecueil (2009, apud OLIVEIRA e FABRICIO, 2011), o desenho paramétrico permite que o arquiteto explore múltiplas alternativas, pois o modelo é interativo, possibilitando, assim, a visualização de diferentes soluções e auxiliando na tomada de decisão. Com isso, uma das vantagens do desenho paramétrico é que se podem explorar novas formas sem a necessidade de criar novos modelos para cada opção de projeto.

O projeto foi modelado através do plugin Grasshopper e a visualizado no software Rhinoceros 6 . Antes de introduzir os dados no programa paramétrico, foi feito um esboço básico (Figura 8) de como se daria a modelagem e como esta se conectaria aos parâmetros. A parametrização se inicia através da identificação do ponto de coordenada $0,0,0$ nos eixos $x, y, z$, ponto previamente definido e demarcado no modelo da área de projeto. A partir desse ponto, foi possível estipular a posição do elemento no plano horizontal, no qual se estabelece os módulos dos triângulos, figura fundamental ao projeto desde o conceito, além de um eixo pelo qual a estrutura poderia se distribuir, aumentando e reduzindo o número de módulos triangulares.

Figura 8: Esboço da modelagem paramétrica.
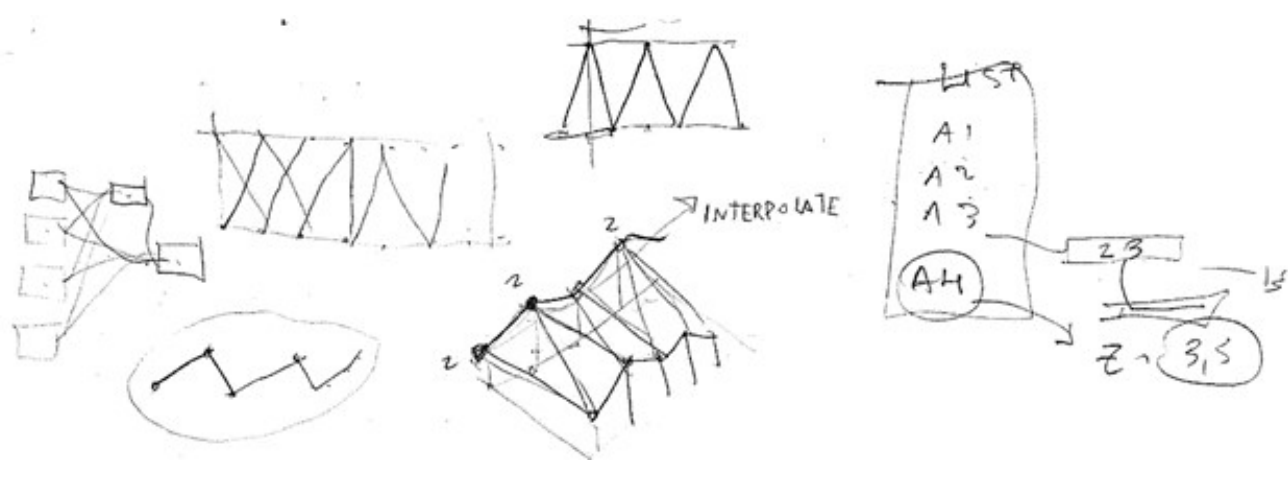

Fonte: Elaborado pelo grupo, 2019.

A modelagem foi raciocinada a partir do volume total, solucionando para o grupo uma problemática que surgiu durante o processo, que era como movimentar os nós da estrutura, sem que estes desconfigurassem a figura base do triangulo isósceles. Com a geometria sendo modelada por completa, os movimentos dos pontos que formam o plano horizontal (eixos x e y) permitiam definir sempre o maior e o menor vão, ou seja, a dimensão básica modular, fazendo com que sempre as dimensões de largura e comprimento sejam proporcionais ao 
módulo triangular e tendo ainda a possibilidade de aumentar ou diminuir o número de módulos. Na Figura 9 é mostrada a vista de topo da estrutura, sem escala.

Figura 9: Vista de topo.

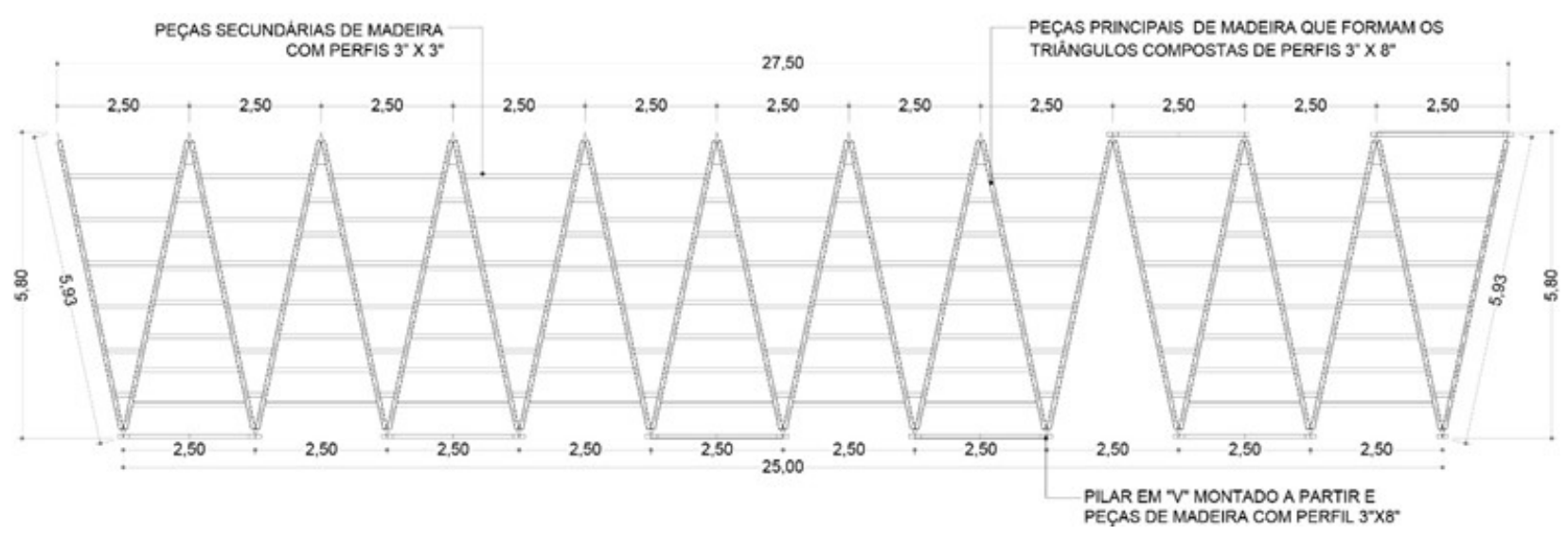

Fonte: Elaborado pelo grupo, 2019.

Quanto ao eixo z, os movimentos dos nós foram isolados permitindo que cada um pudesse ser variado de acordo com a escolha dos projetistas (Figura 10), sendo este movimento vertical o que daria à estrutura uma forma complexa e totalmente individualizada. Poderiam, assim, surgir alternativas do modelo que se adequassem aos vários fatores de projeto, como desnível, altura da estrutura e encaixe nas edificações existentes.

Figura 10: Parâmetros isolados de movimento no eixo z controlados no Grasshopper (direita) e visualizados no Rhinoceros (esquerda).

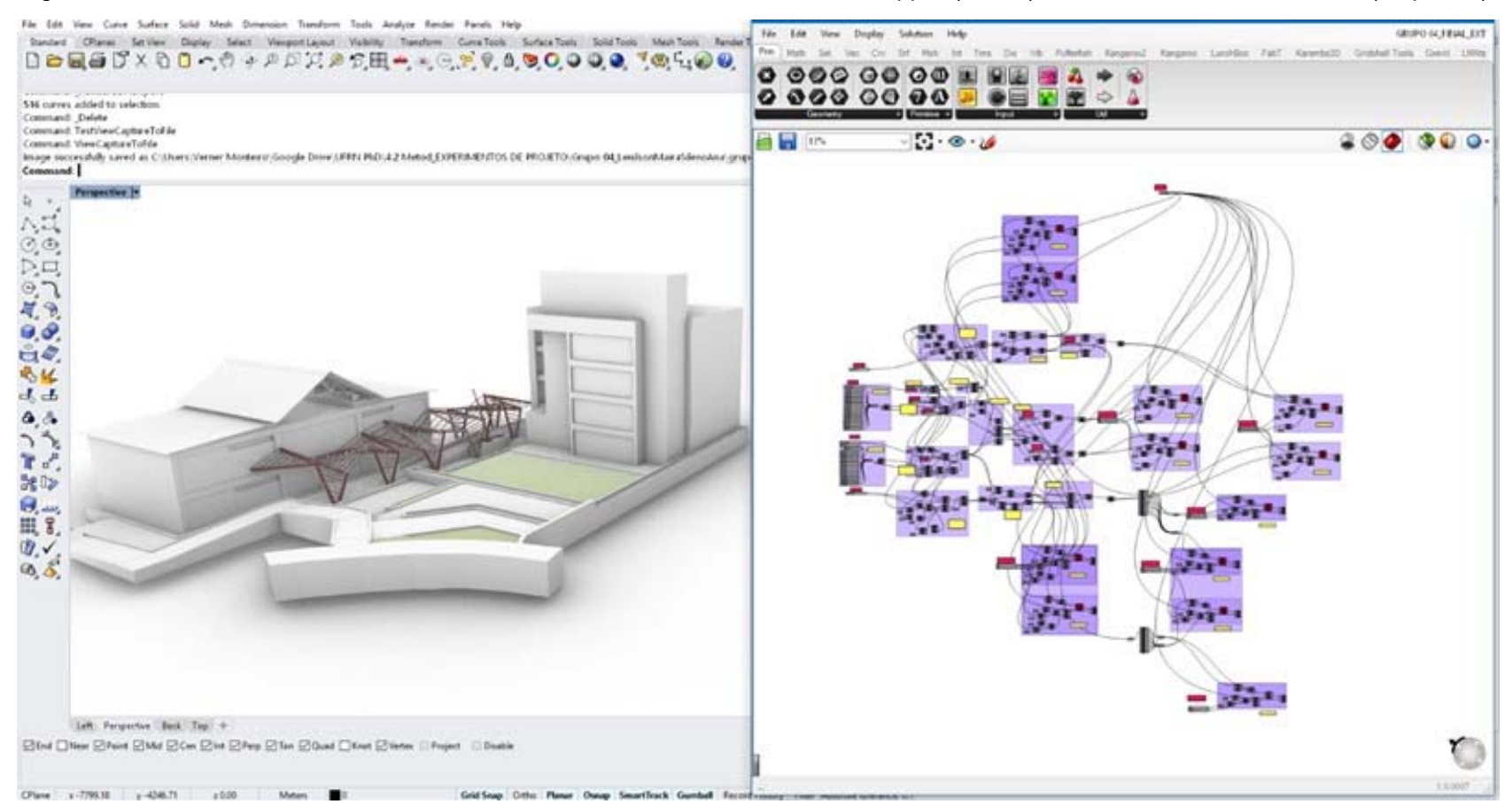

Fonte: Elaborado pelo grupo, 2019.

Durante o processo, a forma foi definida através de linhas que ligavam os pontos que moldavam a estrutura (Figura 11). Assim como observado nos estudos de referências, os pilares não resultavam em um só ponto de apoio. Saíam de um ponto de fundação, porém se ramificavam em dois pontos de apoio para as vigas. Como as edificações existentes possuíam parte de sua estrutura aparente foi optado por conectar pontos das vigas nas estruturas do Galinheiro e do prédio do PPGAU, pois isso reduziria o número de pilares e aumentaria 
a integração entre intervenção nova e edificações pré-existentes. Outra ação importante foi adicionar as barras secundárias (paralelas e em menor dimensão) que poderiam servir de apoio a uma cobertura com telhado ou pérgolas para vegetação e proporcionaria um travamento, reforçando a estrutura primária.

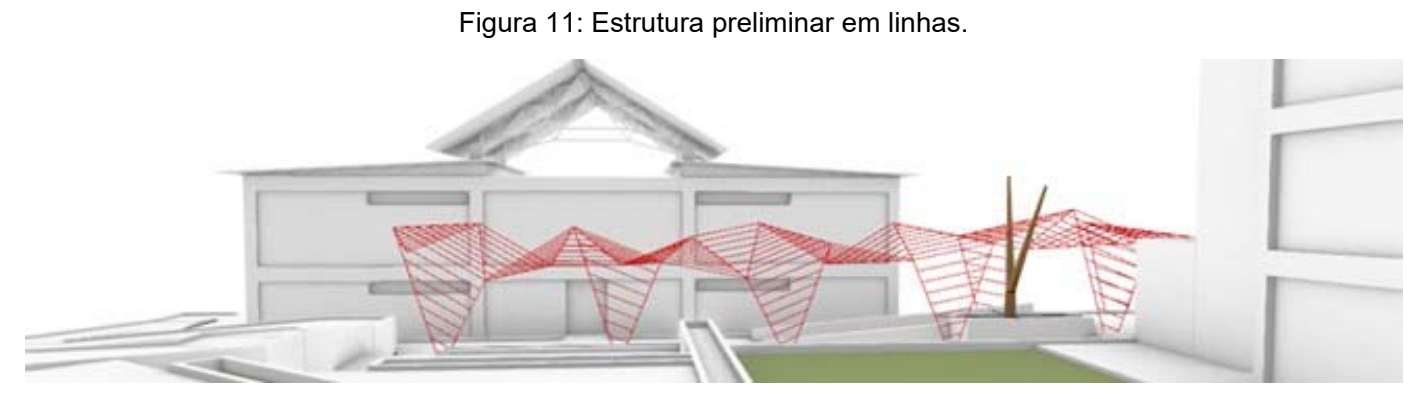

Fonte: Elaborado pelo grupo, 2019.

Definida a forma e o encaixe das peças, visualizou-se o elemento com perfis de madeira (Figura 12). 0 material disponível para o desenvolvimento da proposta é composto por peças de madeira Massaranduba, em diferentes dimensões, usadas principalmente para a execução e manutenção de estruturas em coberturas.

Figura 12: Estrutura com os perfis de madeira selecionados.

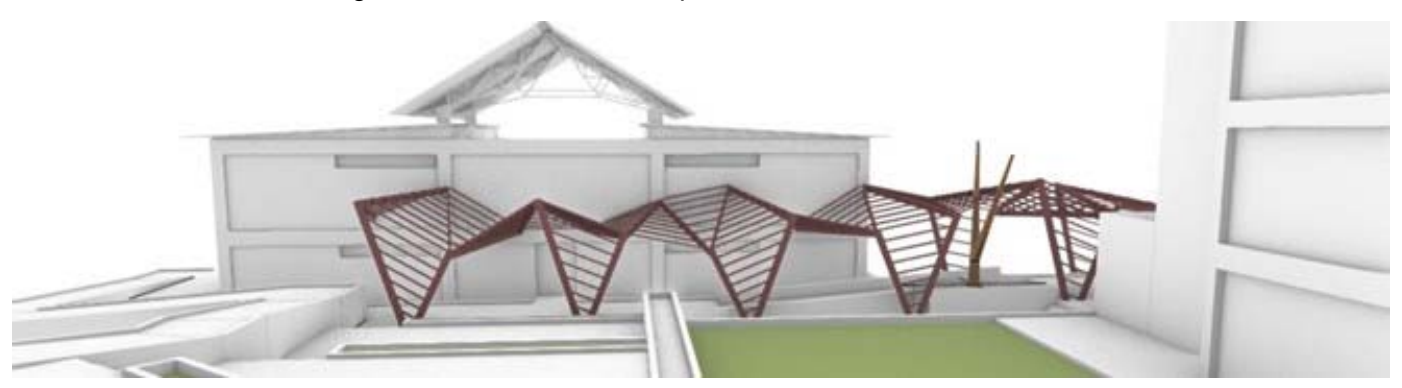

Fonte: Elaborado pelo grupo, 2019.

Após a verificação dos perfis disponíveis, procurou-se por peças que pudessem atuar como pilares e vigas dentro da concepção elaborada, considerando os vãos que se pretende vencer com a estrutura de madeira. Assim, optou-se por usar as peças de maiores dimensões existentes na lista, que são linhas de 3 " x 8" $(7,5 \mathrm{~cm}$ x $20 \mathrm{~cm}$ ), com extensão de 6,00 metros, para desempenhar a função dos elementos principais da estrutura (Figura 13).

Figura 13: Elemento arquitetônico de madeira.

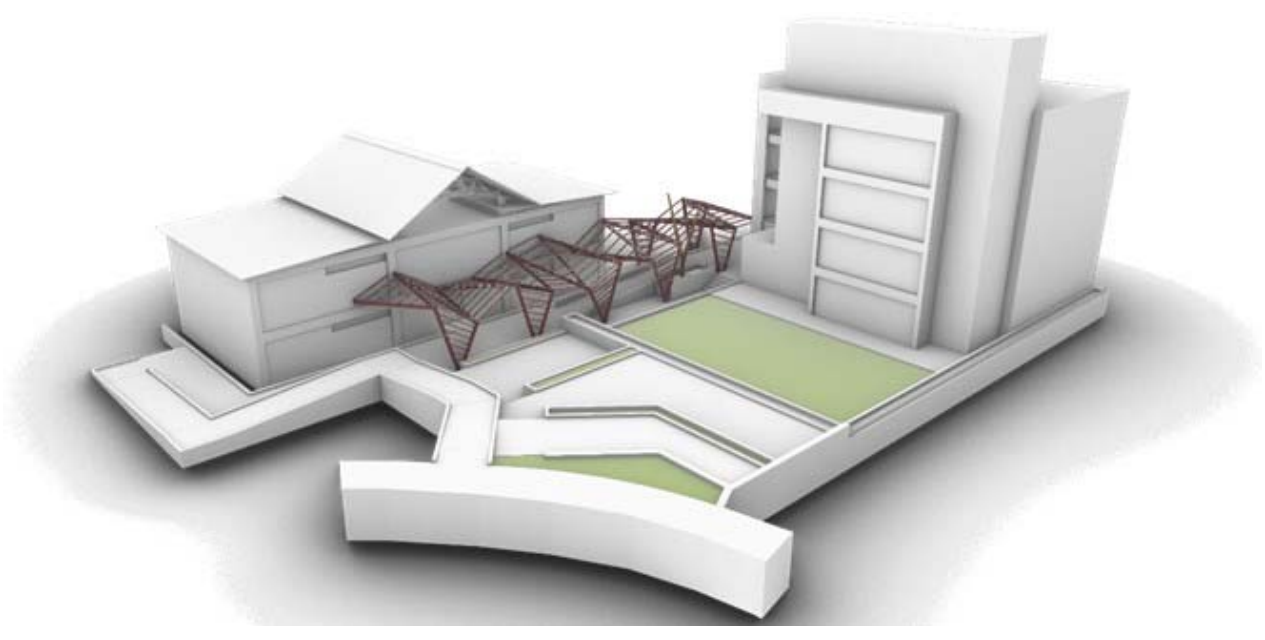

Fonte: Elaborado pelo grupo, 2019. 
Estas dimensões permitiram vencer o vão entre o edifício dos Laboratórios de Arquitetura e o limite do passeio a ser protegido pela cobertura, diminuindo a necessidade de apoios intermediários, deixando os espaços mais livres para o trânsito de pedestres (Figura 14). Além dos pilares e vigas, o projeto prevê perfis de ligação entre os elementos principais. Para estas peças intermediárias, utilizou-se perfis de 3 " x 3 " $(7,5 \mathrm{~cm} \times 7,5 \mathrm{~cm})$ que funcionarão como elementos de amarração entre as peças principais, atuando, também, como pérgulas que ajudarão no desenvolvimento e fixação da espécie vegetal de recobrimento, do tipo trepadeira.

Figura 14: Ponto de vista dos usuários demonstrando os vãos entre o edifício e o limite do passeio.

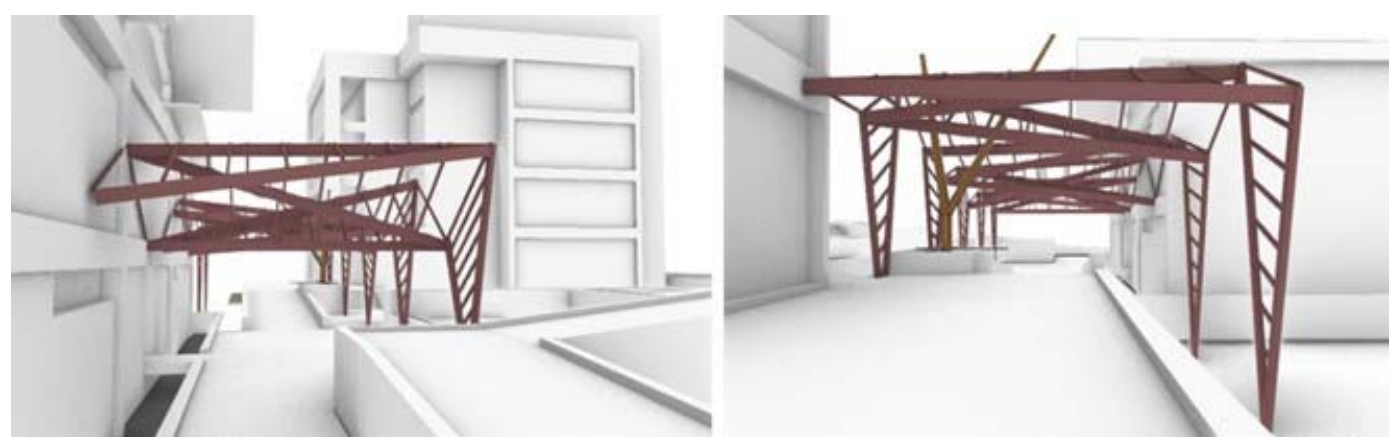

Fonte: Elaborado pelo grupo, 2019.

Para a união dos elementos principais da estrutura, formados por peças de madeira de bitola 3" x 8”, foi necessário o desenvolvimento de elementos de ligação que propiciassem a junção entre pilares e vigas em diferentes ângulos, de acordo com a proposta arquitetônica. Para isso, foi elaborado um modelo de peça do tipo rotulada, que poderá ser produzida em chapas de aço carbono galvanizado, com uso de parafusos de aço inox, devendo ser fixadas nas extremidades dos pilares e vigas de madeira, permitindo a montagem da estrutura com os ângulos previamente definidos em projeto. A Figura 15 mostra a evolução do estudo da peça rotulada: estudo 01, primeiros esboços da peça; estudo 02, desenhos entregues no estudo preliminar; estudo 03, adaptação da peça para prototipagem.

Figura 15: Evolução do estudo da peça de tipo rotulada.

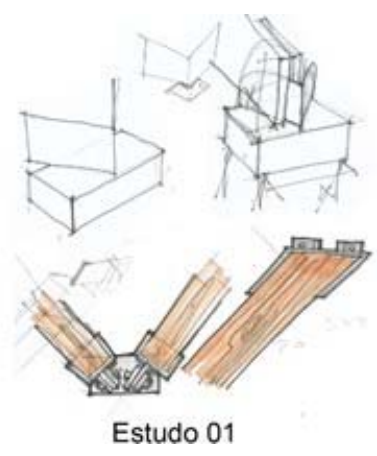

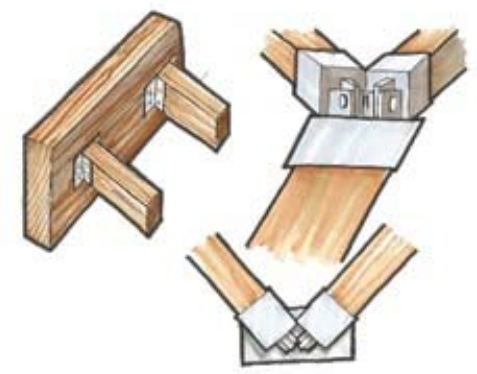

Estudo 02

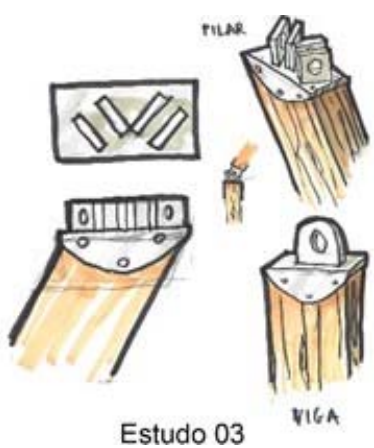

Fonte: Elaborado pelo grupo, 2019

\section{Prototipagem}

Segundo Rodrigues e Fabricio (2011), o modelo paramétrico automatiza o processo de transformar o virtual em real, porque o objeto com informações vetoriais é automaticamente enviado para fabricação ou prototipagem rápida. O computador envia o desenho com coordenadas para produção em corte a laser ou impressão 3D, crescendo assim a utilização dos métodos de fabricação no auxílio ao projeto.

Para a etapa de avaliação do projeto, alguns grupos da atividade de extensão optaram por fazer protótipos. No nosso grupo, foi utilizada a impressão 3D em duas escalas diferentes, a escala de 1:2 para análise dos nós de conexão e a escala de 1:50 para a estrutura por completo. Estas duas maquetes foram importantes ferramentas de estudo da materialidade e volumetria do projeto.

Para atestar a funcionalidade da peça de ligação projetada, foi modelado um protótipo em escala 1:2 (Figura 16), confeccionado em plástico e madeira compensada, com o uso de parafusos metálicos. A partir do modelo

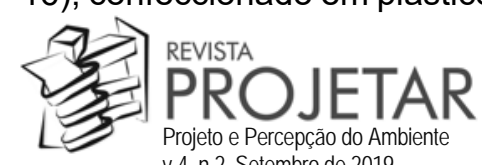


em escala reduzida, foi possível visualizar não só o funcionamento da ligação viga e pilar, mas também um aspecto a ser corrigido na peça. A chapa longitudinal que nasce das vigas e se conecta aos pilares, exercendo a função de rótula, deverá ser mais longa para permitir maior amplitude de movimento ao conjunto, permitindo atingir os ângulos definidos em projeto.

Figura 16: Protótipo em escala 1:2.
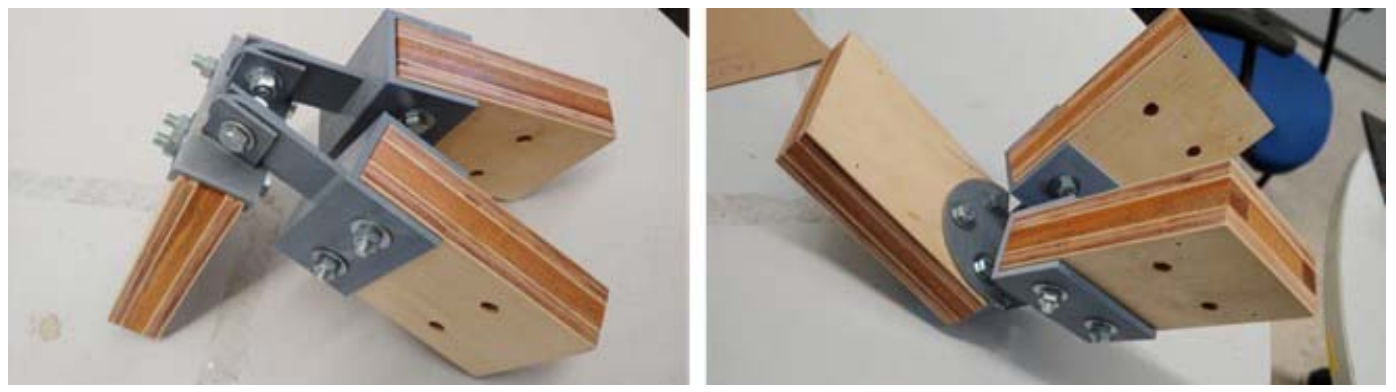

Fonte: Elaborado pelo grupo, 2019.

Peças de desenho semelhante poderão ser utilizadas para a ligação das vigas na fachada do prédio dos Laboratórios de Arquitetura, bem como na fixação dos pilares no piso. As peças, nestes casos, terão a função de permitir o engastamento das vigas na fachada da edificação e dos pilares no solo (Figura 17), evitando o contato da madeira diretamente com o terreno, oferecendo maior durabilidade à estrutura.

Figura 17: Seção do terreno, mostrando posição de fixação de vigas na fachada do galinheiro e pilares no solo.

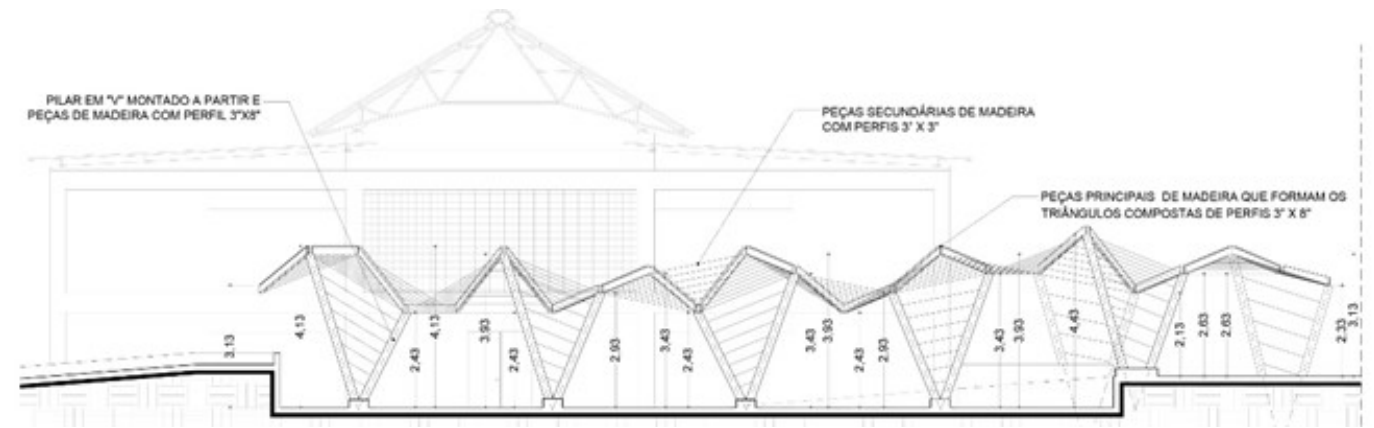

Fonte: Elaborado pelo grupo, 2019.

Já a maquete na escala de 1:50 possibilitou não sóo grupo 04 como também os professores e demais equipes observarem a complexidade formal do elemento arquitetônico (Figura 18). Mesmo em escala muito reduzida em relação ao real, a montagem das peças permitiu uma melhor compreensão quanto à possibilidade de construtibilidade. Entre outros pontos a destacar, ressalta-se que foi necessário maior cuidado na montagem das peças fixando os pilares ao solo e as vigas nas paredes dos edifícios. Para compor o entorno foi utilizado o método de corte a laser de modo a usar um material diferente do protótipo do elemento.

Figura 18: Protótipo em escala 1:50.

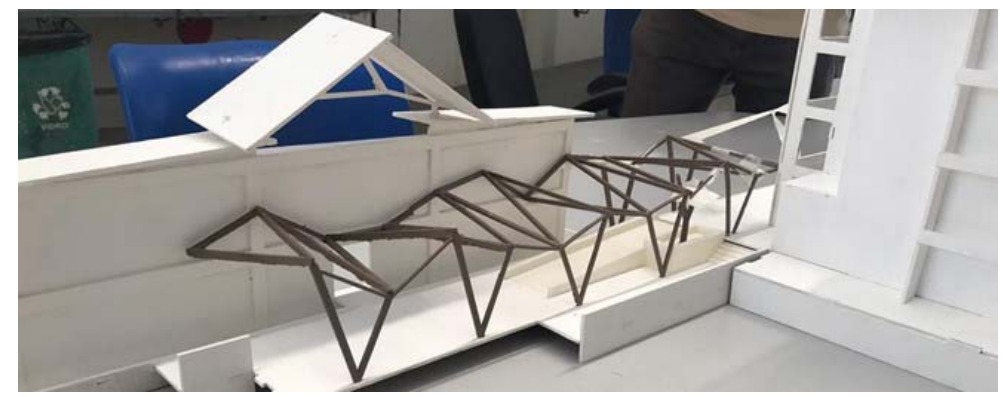

Fonte: Elaborado pelo grupo, 2019. 


\section{Cálculo estrutural}

O modelo estrutural considerado foi pensado de maneira a simplificar a ligação viga-pilar. A ideia principal é que essa ligação seja rotulada. Sendo assim, obrigatoriamente, a ligação do pilar com a fundação deve ser engastada, promovendo a estabilidade do conjunto (Figura 19).

Figura 19: Modelo estrutural proposto

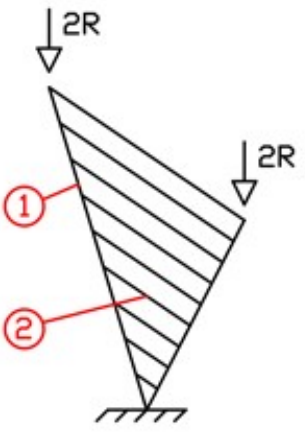

PILAR ENGASTADD

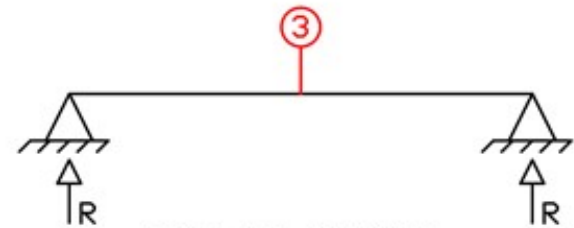

VIGA BI-APQIADA

Fonte: Elaborado pelo grupo, 2019.

O elemento 1 deve ser dimensionado à flexo-compressão, o elemento 2 à flexo-tração e o elemento 3 à flexão simples.

A madeira disponível indicada na lista de materiais fornecida é a Massaranduba. De acordo com a NBR 7190, as propriedades dessa madeira são:

\begin{tabular}{|l|l|}
\hline Massa especifica aparente a 12\% de umidade $-\rho_{a p(12 \%)}$ & $1143 \mathrm{~kg} / \mathrm{m}^{3}$ \\
\hline Resistência à compressão paralela às fibras $-f_{c}$ & $82,9 \mathrm{Mpa}$ \\
\hline Resistência à tração paralela às fibra $-f_{t}$ & $138,5 \mathrm{Mpa}$ \\
\hline Resistência à tração normal às fibras $-f_{t n}$ & $5,4 \mathrm{Mpa}$ \\
\hline Resistência ao cisalhamento $-f_{v}$ & $14,9 \mathrm{Mpa}$ \\
\hline Modulo de elasticidade longitudinal $-E_{c}$ & $22733 \mathrm{Mpa}$ \\
\hline
\end{tabular}

O pré-dimensionamento das peças foi feito levando em consideração a harmonização arquitetônica e a lista de materiais contendo os perfis disponíveis. Os elementos 1 e 3 são perfis 3 "x8" $(7,5 \mathrm{~cm} \times 20 \mathrm{~cm})$ e os elementos 2 são perfis 3 "x3" $(7,5 \mathrm{~cm} \times 7,5 \mathrm{~cm})$.

As cargas consideradas foram:

- $\quad$ Peso próprio $=11,43 \mathrm{kN} / \mathrm{m}^{3}$;

- Permanente $=0,30 \mathrm{kN} / \mathrm{m}^{2}$ (trepadeira ou telha);

- Acidental = $1 \mathrm{kN}$ na posição mais desfavorável, conforme indicado na NBR 6120 para elementos isolados de coberturas.

Uma vez definidos o modelo estrutural, o material, o pré-dimensionamento e as cargas, pode-se então prosseguir para a análise estrutural. Nesta fase, são obtidos os esforços atuantes em cada elemento e a configuração deformada da estrutura. Em seguida, na fase de dimensionamento, comparam-se os esforços atuantes com os esforços resistentes.

Normalmente, as etapas do projeto estrutural acontecem com o auxílio de um software específico para esta finalidade. No caso desse projeto, porém, a análise estrutural pôde ser realizada dentro da mesma plataforma do projeto arquitetônico.

Há um grande número de plugins disponíveis para utilização no Grasshopper. Dentre eles, existe o Karamba3D, uma ferramenta de engenharia estrutural que possibilitou que a análise também fosse realizada de maneira paramétrica. Além do Karamba3D, cálculos manuais foram utilizados para obtenção dos esforços. A seguir, apresentam-se a análise e o dimensionamento das peças, feitos de maneira simplificada para fins de validação do pré-dimensionamento.

- Vigas (elemento 3): 
Figura 20: Diagrama de momento fletor

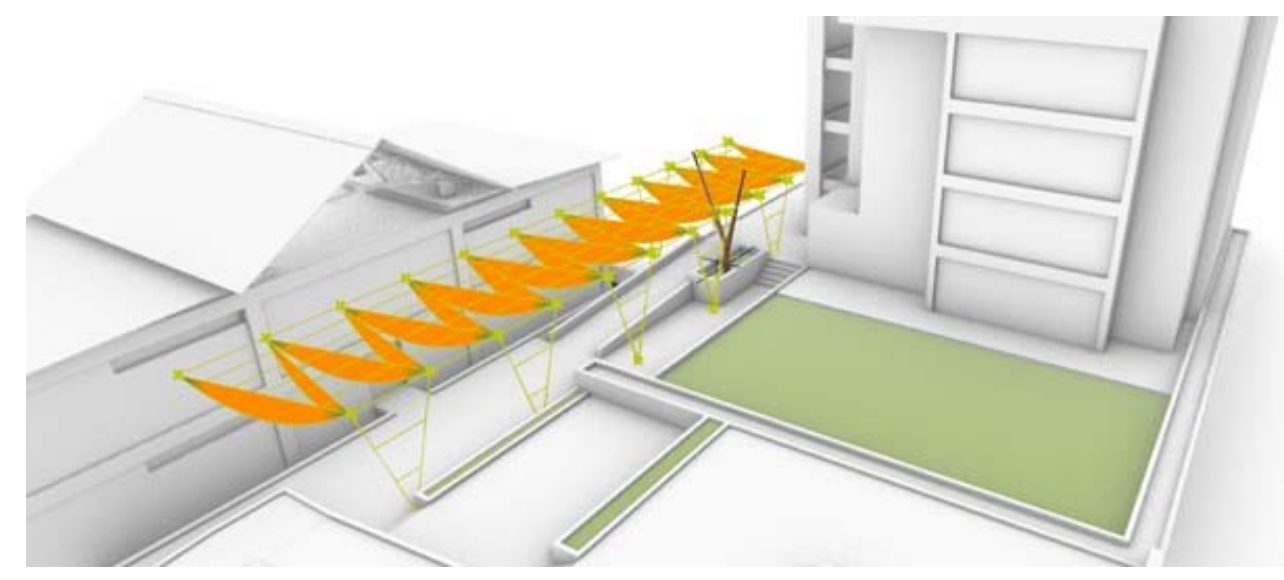

Fonte: Elaborado pelo grupo, 2019.

\begin{tabular}{|l|l|l|l|}
\cline { 2 - 4 } \multicolumn{1}{c|}{} & Resistente & Atuante & Situação \\
\hline Tensão Normal de cálculo (Mpa) & 19,9 & 12,0 & Ok! \\
\hline Tensão Cisalhante de cálculo (Mpa) & 2,1 & 0,3 & Ok! \\
\hline
\end{tabular}

Figura 21: Configuração deformada da estrutura.

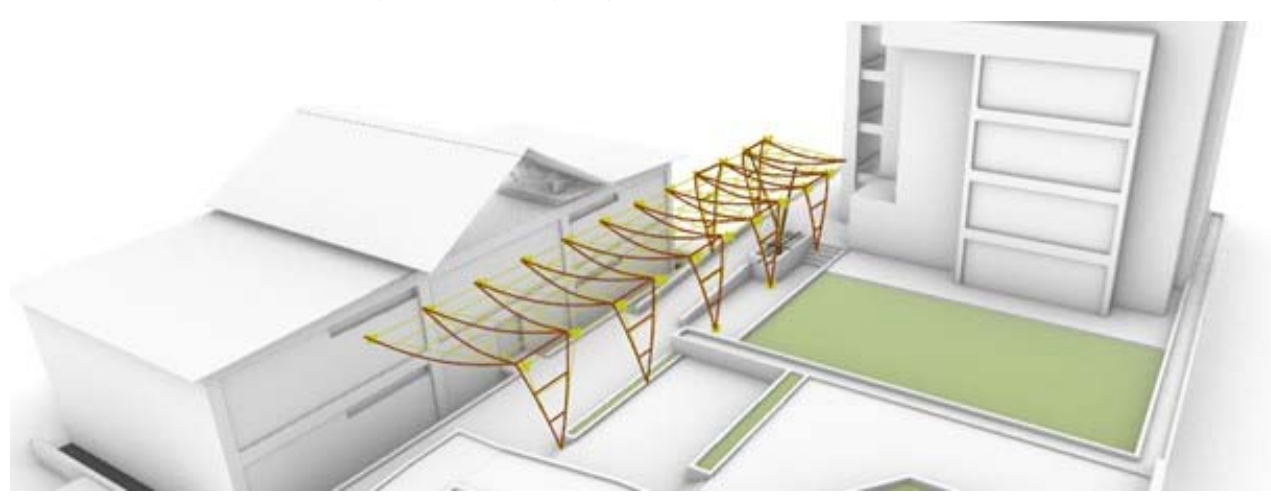

Fonte: Elaborado pelo grupo, 2019.

\begin{tabular}{|l|l|l|l|}
\cline { 2 - 4 } \multicolumn{1}{c|}{} & Estimada & Limite $(\mathrm{L} / 200)$ & Situação \\
\hline Flecha $(\mathrm{cm})$ & 2,97 & 2,04 & Ok! \\
\hline
\end{tabular}


- $\quad$ Pilares (elementos 1 e 2 ):

Figura 22: Diagrama de esforço normal (azul - compressão / laranja - tração)

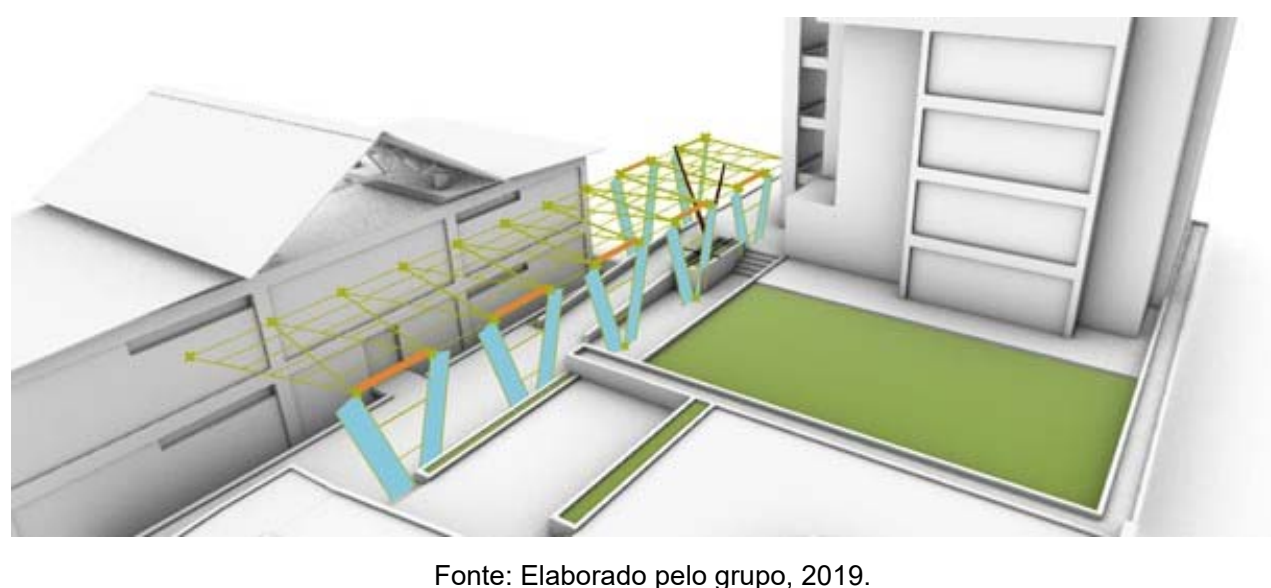

Fonte: Elaborado pelo grupo, 2019.

\begin{tabular}{|l|l|l|l|l|}
\cline { 3 - 5 } \multicolumn{2}{|c|}{} & Resistente & Atuante & Situação \\
\hline Elemento 1 (flexo-compressão) & Tensão Normal de cálculo (Mpa) & 19,9 & 1,0 & Ok! \\
\hline Elemento 2 (flexo-tração) & Tensão Normal de cálculo (Mpa) & 25,9 & 0,4 & Ok! \\
\hline
\end{tabular}

As dimensões das peças obtidas no pré-dimensionamento são compatíveis com os esforços atuantes. É importante ressaltar que as ligações também devem ser calculadas de acordo com esses esforços e executadas de maneira a respeitar o modelo proposto na figura 22.

\section{CONCLUSÃO}

Após o desenvolvimento do projeto, a proposta foi apresentada a uma banca formada por professores e especialista responsáveis por eleger, dentre os seis grupos, a melhor solução projetual para o exercício de concepção, no qual era obrigatório o uso da modelagem paramétrica (através dos softwares Rhinoceros, Grasshopper e o Karamba 3D para o cálculo estrutural). Era também exigido que a forma do objeto arquitetônico fosse passível de variação geométrica por meio de parâmetros definidos.

Dentre as seis propostas apresentadas, o projeto aqui exposto obteve o primeiro lugar do concurso de ideias para a estrutura arquitetônica de forma complexa ligando o prédio dos laboratórios de arquitetura ao prédio do PPGAU. Considerou-se que, em relação às demais, essa solução projetual mostrou-se bem inserida e conectada com os prédios pré-existentes e com as áreas adjacentes, além de se revelar também integrada, no aspecto formal, à estética do conjunto edilício.

Esse exercício mostrou a importância do projeto paramétrico no processo de concepção projetual, dada a facilidade em alterar a geometria do volume, o que permite testar infinitas soluções com formas mais elaboradas e complexas. Além disso, o estudo do projeto através da maquete constituiu um recurso de representação de fundamental importância, adotado desde a definição de intenções iniciais (com a modelagem eletrônica 3D usando o software SketchUp) até à apresentação final de propostas (maquete física), dada a clareza comunicativa e pela aproximação tridimensional que permite ao objeto arquitetônico em definição. 


\section{REFERÊNCIAS}

ABNT, NBR 7190/97 - Projeto de Estruturas de Madeira. Rio de Janeiro.

ABNT, NBR 6120/80 - Cargas para o cálculo de estruturas de edificações. Rio de Janeiro.

ANDRADE, M; RUSCHEL, R; MOREIRA, D. O processo e os métodos. In: KOLWALTOWSKI, Doris K; et al. O Processo de Projeto em Arquitetura: da Teoria à Tecnologia. São Paulo: Oficina de Textos, 2011.

AMARAL, Cláudio Silveira. Descartes e a caixa preta no ensino-aprendizagem da arquitetura. Portal Vitruvius. Arquitextos. Novembro de 2007. Disponível em: <www.vitruvius.com.br/revistas/read/ arquitextos/08.090/194>. Acesso em 28 de julho de 2019.

CHING, F. Desenho para arquitetos. Porto Alegre: Bookman, 2012.

FAVERO, Marcos; PASSARO, Andrés. Senso e conceito no constructo da disciplina projetual: análise projetual como instrumento de trabalho. In: PROJETAR 2005. Anais.... Rio de Janeiro: Proarq/UFRJ Ed., 2005.

LAWSON, B. Como arquitetos e designers pensam. São Paulo: Oficina de Textos, 2011.

LEMOS, Carlos. O que é arquitetura. São Paulo, Brasiliense, 2003, p. 40.

MACIEL, Carlos Alberto. Arquitetura, projeto e conceito. Arquitextos, [s. I.], 2003. Disponível em: <http://www.vitruvius.com.br/revistas/read/arquitextos/04.043/633>. Acesso em 2 agosto 2019.

MCGINTY, Tim. Conceito em arquitetura. In: Introdução à arquitetura. Rio de Janeiro: Campus, 1984.

PFEIL, W; PFEIL, M. Estruturas de madeira. Rio de Janeiro: LTC, 2015.

RODRIGUES, M; FABRICIO, M. Projeto paramétrico e prototipagem rápida: casos em instituições internacionais. In: KOLWALTOWSKI, Doris K; et al. O Processo de Projeto em Arquitetura: da Teoria à Tecnologia. São Paulo: Oficina de Textos, 2011.

SILVA, E. Uma introdução ao projeto arquitetônico. 2. ed. Porto Alegre: UFRGS, 1998.

NOTA DO EDITOR (*) O conteúdo do artigo e as imagens nele publicadas são de responsabilidade do(s) autor(es). 